\title{
Effect of age on lipid profiles in pediatric heart transplant recipients
}

Armstrong AK, Goldberg CS, Crowley DC, Wei W, Gajarski RJ. Effect of age on lipid profiles in pediatric heart transplant recipients.

Pediatr Transplantation 2005: 9: 523-530. ㄷ 2005 Blackwell Munksgaard

Abstract: This study's objectives were to determine if pediatric orthotopic heart transplant (OHT) recipients over all ages develop hyperlipidemia and, secondarily, to identify the effects of immunosuppressive agents and statins on lipid profiles in these patients. Retrospective chart review was performed for pediatric patients transplanted between January 1987 and June 2002. Of the 100 OHTs performed, 50 patients satisfied the inclusion criteria and were grouped by age at OHT as follows: group $1(\mathrm{n}=16)$ : $0-4 \mathrm{yr}$; group $2(\mathrm{n}=10)$ : 5-9 yr; group 3 $(\mathrm{n}=15): 10-14 \mathrm{yr}$; group $4(\mathrm{n}=9): 15-18 \mathrm{yr}$. There were 2789 lipid levels recorded, and each patient had an average of 14 post-

OHT lipoprotein panels measured. Post-OHT total cholesterol and low-density lipoprotein (LDL) levels were significantly greater than those of the general population for the entire follow-up period in all age groups, except for LDL levels in group 2. Cyclosporin level and prednisone dose were positively associated with total cholesterol and LDL levels $(\mathrm{p}<0.03)$. Statins significantly decreased total cholesterol and LDL levels $(\mathrm{p}<0.001)$. Hyperlipidemia affects OHT patients of all ages. Even the youngest patients may benefit from immunosuppression using an alternative to cyclosporin, such as tacrolimus, and steroid-free regimens, which may improve lipid profiles. Once safety and efficacy

data are available, all age groups may benefit from statins.

\section{Aimee K. Armstrong ${ }^{1}$, Caren S. Goldberg', Dennis C. Crowley ${ }^{1}$, Wei Wei ${ }^{2}$ and Robert J. Gajarski ${ }^{1}$}

${ }^{1}$ Division of Pediatric Cardiology, Department of Pediatrics and Communicable Diseases, University of Michigan Health System, Ann Arbor, ${ }^{2}$ Department of Biostatistics, University of Michigan School of Public Health, Ann Arbor, MI, USA

Key words: heart transplantation - pediatric hyperlipidemia - immunosuppression

Aimee K. Armstrong, MD, Division of Pediatric Cardiology, University of Michigan Health System, L1242 Women's, Box 0204, 1500 East Medical Center Drive, Ann Arbor, Michigan 48109-0204, USA

Tel.: 7347645177

E-mail: aimeearm@umich.edu

Accepted for publication 4 January 2004
OHT is associated with multiple comorbidities, including hyperlipidemia, which is usually secondary to immunosuppressive agents. CyA and prednisone have been implicated as the main contributors to elevated lipid levels (1-5). Hyperlipidemia has been shown to play a role in the development of graft CAV (6-8). Specifically, the combination of hypercholesterolemia and immunologic injury, to which peri-OHT graft ischemia and rejection may contribute, leads to extensive, rapidly progressive atheroarteriosclerosis (6). Generally, because of the diffuse nature of its microvascular involvement, CAV cannot be successfully treated using percutaneous or surgical

\footnotetext{
Abbreviations: AZA, azathioprine; BMI, body mass index; $\mathrm{CAV}$, coronary artery vasculopathy; CyA, cyclosporin A; HDL, high-density lipoprotein; ISHLT, International Society for Heart and Lung Transplantation; LDL, lowdensity lipoprotein; MMF, mycophenolate mofetil; NCEP, National Cholesterol Education Program; OHT, orthotopic heart transplant.
}

revascularization. Data from both the adult and pediatric transplant registries found that CAV is an important cause of death in all OHT patients and has been linked to $40 \%$ of all pediatric deaths beyond 3 yr post-OHT (9). Therefore, prevention of CAV by aggressively treating precipitating factors, such as hyperlipidemia, has become a primary focus in patient management (8).

While studies have demonstrated that hyperlipidemia occurs in pediatric patients after OHT (10-12), age-related variations have not been systematically investigated. In the present study, we hypothesized that hyperlipidemia affects pediatric OHT patients of all ages. Secondarily, we sought to identify the risk factors for hyperlipidemia and to assess the efficacy of hydroxymethylglutaryl-CoA reductase inhibitors (statins).

\section{Patients and methods}

\section{Patient sample and data collection}

Following institutional review board approval and consent waiver, lipoprotein profiles of all OHT recipients who 


\section{Armstrong et al.}

underwent transplantation at C.S. Mott Children's Hospital between January, 1987 and June, 2002 and who survived to hospital discharge were retrospectively reviewed. Patients were excluded who were $\geq 18$ yr of age at the time of OHT, died in the month following OHT, were followed exclusively at another institution, or were multi-organ transplant recipients. Each patient's medical record was reviewed and all pre- and post-OHT serum lipid levels, including total cholesterol, HDL, LDL, and triglyceride levels were recorded. Potential risk factors for hyperlipidemia, including immunosuppressive regimens, CyA levels, treatment for rejection, BMI, and gender, were also recorded. BMI was defined as elevated if it was $\geq 75$ th percentile for age, compared with healthy historical controls (13). The patients were grouped by age at OHT as follows: group 1: $0-4 \mathrm{yr}$, group 2: 5-9 yr, group 3: 10-14 yr, group 4: 15-18 yr. These age groups were chosen in order to compare the patients' lipid levels to healthy historical control data published by the NCEP (14) (Table 1). Of note, these average cholesterol and LDL levels are similar across all pediatric age groups and between genders.

\section{Lipoprotein measurements}

When available, pre-OHT levels were recorded. Fasting post-OHT levels were drawn at the time of surveillance endomyocardial biopsies, which were typically performed 2-4 wk post-OHT, monthly for 3 months, every other month for 6 months, and every 6-12 months thereafter, depending on rejection history.

\section{Immunosuppression}

Prior to September 1998, the primary immunosuppressive regimen consisted of CyA, corticosteroids, and AZA. Thereafter, MMF was used in place of AZA. One patient was managed with tacrolimus rather than CyA for part of the follow-up period. CyA was given in a continuous infusion at $0.5-2 \mathrm{mg} / \mathrm{h}$, beginning immediately postoperatively. This was changed to oral dosing of $4-5 \mathrm{mg} / \mathrm{kg} /$ dose twice daily, when a patient was tolerating oral medications. Doses were adjusted to maintain levels of 200-350 ng/mL during the first post-OHT year and $100-200 \mathrm{ng} / \mathrm{mL}$ thereafter, in conjuction with biopsy scores of $\leq$ ISHLT grade 2 .

Table 1. Healthy historical control data published by the National Cholesterol Education Program

\begin{tabular}{lll}
\hline & & \\
Age $(\mathrm{yr})$ & Cholesterol $[(\mathrm{mg} / \mathrm{dL})$ 50th percentile $]$ & $\begin{array}{l}\text { LDL }[(\mathrm{mg} / \mathrm{dL}) \\
50 \text { th percentile] }\end{array}$ \\
\hline Males & & $\mathrm{N} / \mathrm{A}$ \\
$0-4$ & 156 & 93 \\
$5-9$ & 164 & 97 \\
$10-14$ & 160 & 96 \\
$15-19$ & 150 & \\
Females & & $\mathrm{N} / \mathrm{A}$ \\
$0-4$ & 161 & 101 \\
$5-9$ & 168 & 97 \\
$10-14$ & 163 & 96 \\
$15-19$ & 160 & \\
\hline
\end{tabular}

$\mathrm{N} / \mathrm{A}$, not applicable.

NCEP report (14).
Table 2. Prednisone daily doses

\begin{tabular}{llll}
\hline Age (yr) & Low dose (mg/day) & Medium dose (mg/day) & High dose (mg/day) \\
\hline $0-4.9$ & $0.25-1.5$ & $1.6-4.9$ & $\geq 5.0$ \\
$5-11.9$ & $0.25-4.9$ & $5.0-14.9$ & $\geq 15.0$ \\
$\geq 12$ & $0.25-14.9$ & $15.0-24.9$ & $\geq 25.0$ \\
\hline
\end{tabular}

Methylprednisolone $(30 \mathrm{mg} / \mathrm{kg})$ i.v. was administered during reperfusion of the donor organ, followed by $2 \mathrm{mg} /$ $\mathrm{kg}$ /day divided twice daily, starting in the immediate postoperative period. This was weaned incrementally until a target maintenance dose of $0.5 \mathrm{mg} / \mathrm{kg} /$ day was achieved. Intravenous corticosteroids were changed to oral prednisone as tolerated. The prednisone was weaned further and occasionally discontinued, depending on the individual patient rejection histories. For the purposes of this study, prednisone doses were determined to be 'low,' 'medium,' or 'high' for three age groups, as shown in Table 2.

Beginning on the second postoperative day, AZA was initiated at $1 \mathrm{mg} / \mathrm{kg}$ /day once daily intravenously or orally. The dose was increased to a maximum of $2 \mathrm{mg} / \mathrm{kg} / \mathrm{day}$ and adjusted to maintain a white blood cell count $>4000$. After MMF replaced AZA, patients received oral MMF at a dose of $1200 \mathrm{mg} / \mathrm{m}^{2} /$ day (maximum $3 \mathrm{~g}$ ). The dose was adjusted to maintain white blood cell counts $>4000$ and to minimize gastrointestinal side effects.

Episodes of ISHLT grade 3A rejection or greater were treated with a bolus of corticosteroids, either intravenous methylprednisolone $30 \mathrm{mg} / \mathrm{kg} /$ day (maximum $1 \mathrm{~g} / \mathrm{day}$ ) or oral prednisone $10 \mathrm{mg} / \mathrm{kg} /$ day (maximum $100 \mathrm{mg} /$ day) for three consecutive days. Occasionally, episodes of ISHLT grade 2 rejection were treated with steroids, depending on the patient's rejection history and time from OHT.

\section{Statin use}

Post-OHT, a subset of patients were started on either pravastatin $10 \mathrm{mg}$ once daily or atorvastatin $10 \mathrm{mg}$ once daily for fasting total cholesterol levels $>200 \mathrm{mg} / \mathrm{dL}$. LDL levels were not used as criteria for starting statins, during the study period. The statin doses were increased to $20-30 \mathrm{mg}$ once daily to maintain cholesterol levels $<200 \mathrm{mg} / \mathrm{dL}$.

\section{Statistical analysis}

Numeric data is expressed as a mean with standard deviations, unless otherwise specified. Distributions of lipid levels initially were examined using histograms. PreOHT lipid levels were compared with normal values for healthy historical control data by one sample $t$-tests. To avoid bias of variable timing and number of post-OHT lipid levels for each patient and to adjust for multiple potential confounding variables, linear mixed effects models were used to compare lipid levels for each age group to normal values and to examine the effects of immunosuppressive agents, statins, and demographic characteristics. Lipid levels pre- and post-statin use were compared using paired $t$-tests. In order to explore further the relationship of age and lipid levels, simple linear regression was performed to compare the highest lipid levels post-OHT to age at the time of the lipid measurements. Statistical analyses were performed using SAS/ STAT software, version 6 (SAS Institute Inc., Cary, NC, USA) and the R software, version 1.7.0. 


\section{Results}

Patient demographics

During the study period, 100 OHTs were performed in 97 patients. Because of the large number of adult patients and patients who had follow-up at outside institutions, 50 patients (33 males and 17 females), including two re-transplants, satisfied the inclusion criteria. The average patient age at the time of OHT was $8.9 \pm 5.5 \mathrm{yr}$ (range $0.2-17.3 \mathrm{yr}$ ). Mean followup time was $5.6 \pm 4.3 \mathrm{yr}$ (range $0.2-15.5 \mathrm{yr}$ ), and $44 \%$ of the patients were followed for $>5 \mathrm{yr}$. There were 16 patients in group 1 (0-4 yr), six of whom were 12-24 months of age, 10 in group 2 (5-9 yr), 15 in group 3 (10-14 yr), and nine in group 4 (15-18 yr). The study population was $76 \%$ white, $22 \%$ African American, and 2\% Hispanic. Pre-OHT diagnoses included congenital heart disease (42\%), dilated cardiomyopathy (34\%), hypertrophic cardiomyopathy $(8 \%)$, restrictive cardiomyopathy $(6 \%)$, adriamycin-induced cardiomyopathy $(6 \%)$, and vasculopathy of a previous allograft $(4 \%)$.

\section{Lipoprotein levels}

A total of 2789 lipid levels were recorded. PreOHT total cholesterol and LDL levels were available for 58 and $36 \%$ of the patients, respectively. In addition to the pre-OHT levels, each patient had an average of 14 (range 0-41) lipoprotein panels drawn post-OHT. Group 1 included one patient who was transplanted at $<1 \mathrm{yr}$ of age and was included in the analysis, as this patient had a pre-OHT profile. This patient's post-OHT levels were excluded, however, as it was unclear that they were drawn in the fasting state. This was the only patient with no postOHT levels.

\section{Lipoprotein levels over time}

\section{Total cholesterol}

The weighted mean total cholesterol levels for each group as a function of post-OHT time are shown in Fig. 1. For comparison, the average for healthy historical controls $(160 \mathrm{mg} / \mathrm{dL})$ and the treatment threshold chosen by many OHT physicians $(200 \mathrm{mg} / \mathrm{dL})$ are superimposed on the graph. Levels from patients taking statins were excluded. Table 3 lists the number of patients in each group at each time period. The pre-OHT levels were less than normal values for healthy historical controls $(\mathrm{p}<0.001)$. Using a linear mixed effects model, post-OHT levels for all groups remained significantly above the average

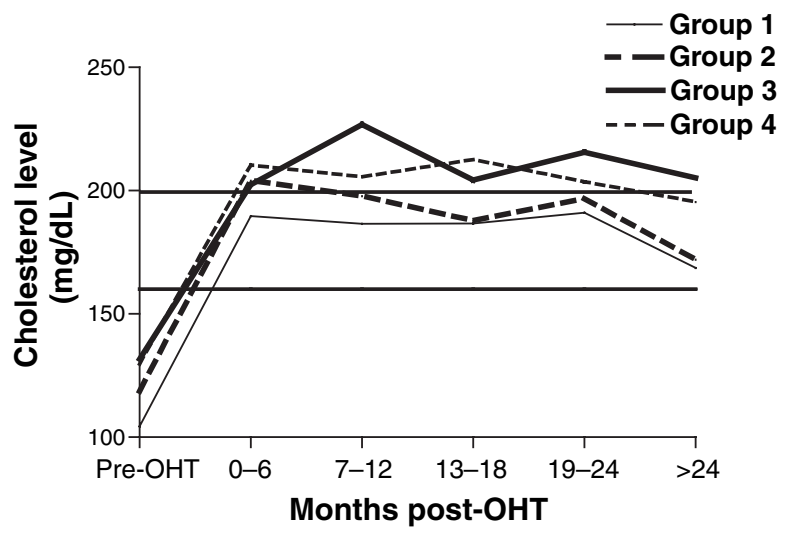

Fig. 1. Weighted mean total cholesterol levels for each age group as a function of pre- and post-OHT time. The horizontal lines represent the treatment threshold of $200 \mathrm{mg} / \mathrm{dL}$ and the average for healthy historical controls of $160 \mathrm{mg} /$ dL. Levels from patients taking statins were excluded from this graph. Post-OHT levels for all groups remained significantly above the average for historical controls $(\mathrm{p} \leq 0.007)$.

Table 3. Number of patients in Fig. 1 in each group and each time period

\begin{tabular}{lcccccc}
\hline Group & Pre-OHT & $\begin{array}{l}\text { 0-6 } \\
\text { months }\end{array}$ & $\begin{array}{l}\text { 7-12 } \\
\text { months }\end{array}$ & $\begin{array}{l}\text { 13-18 } \\
\text { months }\end{array}$ & $\begin{array}{l}\text { 19-24 } \\
\text { months }\end{array}$ & $\begin{array}{l}>24 \\
\text { months }\end{array}$ \\
\hline 1 & 5 & 14 & 14 & 12 & 10 & 13 \\
2 & 7 & 9 & 9 & 10 & 4 & 8 \\
3 & 11 & 13 & 13 & 10 & 9 & 12 \\
4 & 6 & 9 & 8 & 8 & 6 & 4 \\
\hline
\end{tabular}

for historical controls ( $\mathrm{p} \leq 0.007$ ). For the majority of the follow-up period, the patients 10-18 yr of age had levels $>200 \mathrm{mg} / \mathrm{dL}$, and the levels remained elevated throughout the followup period. Of the six patients transplanted between 1 and $2 \mathrm{yr}$ of age, five patients had post-OHT cholesterol levels $>200 \mathrm{mg} / \mathrm{dL}$ by the time they were $3.4 \mathrm{yr}$ of age.

For more than half of the follow-up time, $86 \%$ of patients not taking statins (age at OHT $9.3 \pm 5.4 \mathrm{yr}$ ) had cholesterol levels greater than the average for healthy children, and $36 \%$ (age at OHT $12.4 \pm 3.8 \mathrm{yr}$ ) had cholesterol levels $>200 \mathrm{mg} / \mathrm{dL}$. In order to compare the results to other published studies, 1- and 3-yr post-OHT levels were assessed for patients not taking statins. At the 1- and 3-yr follow-up visits, 40 and $34 \%$ of these patients, respectively, had total cholesterol levels $>200 \mathrm{mg} / \mathrm{dL}$.

\section{Low-density lipoprotein}

The post-OHT weighted mean LDL levels for each group are shown in Fig. 2. One superimposed horizontal line defines the arbitrary treatment threshold $(100 \mathrm{mg} / \mathrm{dL})$ used by many 


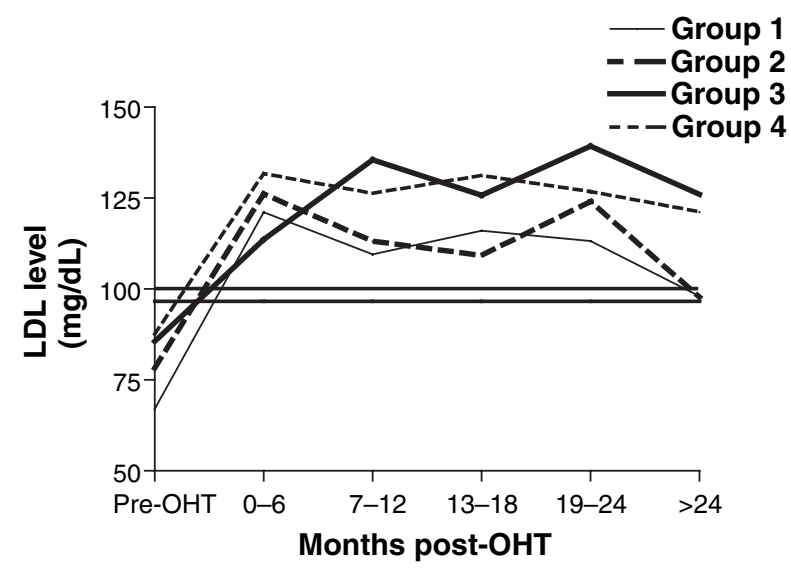

Fig. 2. Weighted mean LDL levels for each age group as a function of pre- and post-OHT time. The horizontal lines represent the treatment threshold of $100 \mathrm{mg} / \mathrm{dL}$ and the average LDL for healthy historical controls of $97 \mathrm{mg} / \mathrm{dL}$. Levels from patients taking statins were excluded from this graph. Post-OHT levels for all groups, except group 2, were significantly above the average and above the treatment threshold $(\mathrm{p} \leq 0.002)$.

Table 4. Number of patients in Fig. 2 in each group and each time period

\begin{tabular}{lllllll}
\hline Group & Pre-OHT & $\begin{array}{l}\text { 0-6 } \\
\text { months }\end{array}$ & $\begin{array}{l}\text { 7-12 } \\
\text { months }\end{array}$ & $\begin{array}{l}\text { 13-18 } \\
\text { months }\end{array}$ & $\begin{array}{l}19-24 \\
\text { months }\end{array}$ & $\begin{array}{l}>24 \\
\text { months }\end{array}$ \\
\hline 1 & 2 & 14 & 13 & 12 & 10 & 13 \\
2 & 6 & 9 & 9 & 10 & 4 & 8 \\
3 & 5 & 11 & 13 & 9 & 9 & 12 \\
4 & 5 & 9 & 8 & 8 & 6 & 4 \\
\hline
\end{tabular}

physicians in conjunction with total cholesterol levels $>200 \mathrm{mg} / \mathrm{dL}$, and the other marks the average LDL for healthy children $(97 \mathrm{mg} / \mathrm{dL})$. Levels from patients taking statins were excluded from this graph. Table 4 shows the number of patients in each group at each time period. The pre-OHT LDL levels tended to be lower than normal values for healthy historical controls $(\mathrm{p}=0.05)$. Using the linear mixed effects model, all of the groups, except group $2(p=0.3)$, remained significantly above the average and above the treatment threshold throughout follow-up ( $\mathrm{p} \leq 0.002$ ). Of the six patients transplanted between 1 and $2 \mathrm{yr}$ of age, five patients had post-OHT LDL levels $>100 \mathrm{mg} / \mathrm{dL}$ by the time they were $3.4 \mathrm{yr}$ of age.

For more than half of the follow-up time, 74\% of patients not taking statins (age at OHT $9.3 \pm 5.2 \mathrm{yr}$ ) had LDL levels greater than average, and $64 \%$ of patients (age at OHT $10.1 \pm$ $4.8 \mathrm{yr}$ ) had LDL levels $>100 \mathrm{mg} / \mathrm{dL}$. At the 1 - and 3-yr follow-up visits, 15 and $14 \%$ of these patients, respectively, had LDL levels $>160 \mathrm{mg} / \mathrm{dL}$.

\section{High-density lipoprotein}

The pre-OHT HDL levels were significantly lower than normal values for healthy historical controls $(\mathrm{p}<0.001)$. Post-OHT, the average HDL level was $49 \pm 3 \mathrm{mg} / \mathrm{dL}$ and not significantly different from the average normal value of $54 \mathrm{mg} / \mathrm{dL}$.

\section{Triglycerides}

The pre-OHT triglyceride levels were higher than those of the historical controls $(p=0.04)$. Similarly, the average post-OHT triglyceride level was $162 \pm 24 \mathrm{mg} / \mathrm{dL}$, which was significantly higher than the average normal value of $62 \mathrm{mg} / \mathrm{dL}$ $(\mathrm{p}<0.001)$.

Effect of rejection, immunosuppressive agents, and statins

\section{Rejection}

The 50 patients had a total of 140 episodes of treated rejection during the study period, and $50 \%$ of these episodes occurred in the first postOHT year. There was an average of 0.50 episodes per patient-year of follow-up (group 1: 0.34, group 2: 0.50, group 3: 0.46, group 4: 1.0). While maintenance steroid dose was evaluated for its impact on lipid levels (discussed later in this section), rejection treatment was not. Because of the low individual patient rejection frequency, the usual steroid pulse used for treatment of rejection should not have had long-term effects on lipids, and $33 \%$ of the rejection episodes were associated with low CyA levels, which biases the statistical analysis.

\section{Cyclosporin}

As shown in Table 5, adjusting for prednisone dose, statin use, AZA and MMF use, gender, and age, CyA level was positively associated with cholesterol $(p<0.001)$ and LDL levels $(\mathrm{p}<0.001)$.

\section{Corticosteroids}

Likewise, adjusting for similar factors, prednisone dose was also positively associated with

Table 5. Association of immunosuppressive agents and statins with the concentration of serum total cholesterol and LDL

\begin{tabular}{lllllr}
\hline & \multicolumn{2}{l}{ Total cholesterol } & & \multicolumn{2}{l}{ LDL } \\
\cline { 6 - 7 } \cline { 6 - 7 } & Change & p-value & & Change & p-value \\
\hline Cyclosporin & $\uparrow$ & $<0.001$ & & \\
Prednisone & $\uparrow$ & 0.007 & & $<0.001$ \\
AZA/MMF & - & 0.948 & & - & 0.025 \\
Statin & $\downarrow$ & $<0.001$ & & \\
& & & & & $<0.008$ \\
\hline
\end{tabular}

LDL, low density lipoprotein; $\uparrow$, increase; $\downarrow$, decrease; -, no change. 
cholesterol $(\mathrm{p}=0.007)$ and LDL levels $(\mathrm{p}=$ 0.025). The 'low,' 'medium,' and 'high' prednisone doses were adjusted for in the statistical model.

\section{Mycophenolate mofetil and azathioprine}

AZA and MMF were not associated with a significant change in cholesterol or LDL levels $(\mathrm{p}>0.7)$.

\section{Statins}

Sixteen of the 50 study patients were started on statins at an average age of $16.5 \mathrm{yr}$ (range 6.8-26.1 yr). Using the linear mixed effects model, statins were associated with a significant decrease in cholesterol $(p<0.001)$ and LDL levels $(\mathrm{p}<0.001)$. Statins decreased total cholesterol by $16 \%$ from 211 to $178 \mathrm{mg} / \mathrm{dL}$ ( $\mathrm{p}=$ $0.003)$, but the post-statin levels remained greater than normal for healthy children $(\mathrm{p}=0.02)$. Statins also reduced LDL levels by $24 \%$ from 128 to $97 \mathrm{mg} / \mathrm{dL} \quad(\mathrm{p}=0.007)$, which is the average value for healthy children.

\section{Effect of age}

The effect of age on lipoprotein profiles was assessed, using the linear mixed effects model. For this analysis, data collected from patients while they were taking statins were excluded. Compared with the other groups, each of the four age groups had significantly different total cholesterol $(\mathrm{p}=0.024)$ and LDL curves over time $(\mathrm{p}<0.001)$. These curves are shown in Figs 1 and 2. Despite having different curve patterns, at a fixed time period post-OHT, there was no significant difference in total cholesterol $(p=0.2)$ or in LDL levels between the four age groups $(p=0.2)$. In addition, the highest post-OHT total cholesterol level for each patient, when he or she was not on

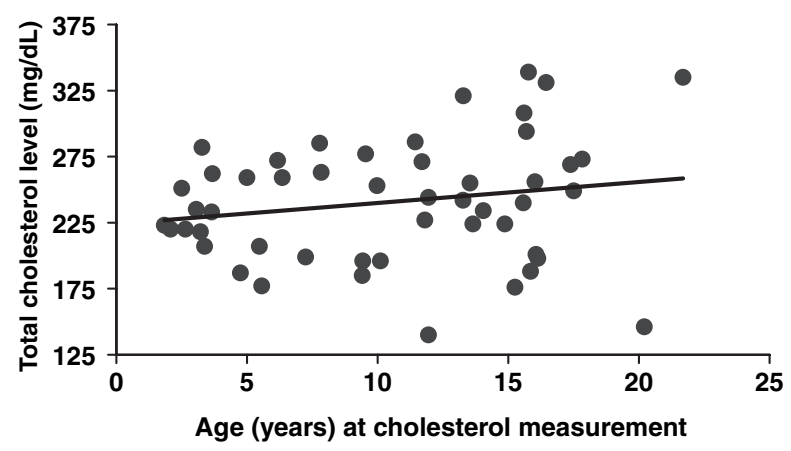

Fig. 3. Relationship of age and highest total cholesterol level post-OHT for patients not taking statins. $R^{2}=0.04$; $\mathrm{p}=0.2$. statins, was compared with the age at the time of the measurement (Fig. 3), and a linear regression model showed no relationship between the two $\left(R^{2}=0.04, \mathrm{p}=0.2\right)$. Similar analysis for LDL also revealed no relationship $\left(R^{2}=0.02, \mathrm{p}=0.3\right)$.

Neither gender $(p>0.2)$ nor BMI $(p>0.4)$ affected total cholesterol, LDL, HDL, or triglyceride levels in the study population.

\section{Discussion}

The primary focus of this study was to assess the effect of age on hyperlipidemia. Obscuring this effort was the lack of strictly defined levels of total cholesterol and LDL, which mandate treatment in this population. By necessity, we compared the study patients' lipid levels to normal values for healthy historical controls, to treatment thresholds currently practiced by many OHT physicians, and to levels defined as hyperlipidemia in other studies.

Regardless of the definition, this study demonstrated that hyperlipidemia is common after pediatric OHT, occurs in all pediatric age groups, and appears to persist throughout follow-up. At 1-yr post-OHT, $40 \%$ of our patients had total cholesterol levels $>200 \mathrm{mg} /$ $\mathrm{dL}$, which is similar to $36 \%$ reported by Seipelt et al. (10). At $3 \mathrm{yr}$ post-OHT, $34 \%$ of our patients had levels $>200 \mathrm{mg} / \mathrm{dL}$. At 1- and 3-yr post-OHT, 15 and $14 \%$ of patients, respectively, had LDL levels $>160 \mathrm{mg} / \mathrm{dL}$. Similarly, DiFilippo et al. (12) showed that total cholesterol and LDL increase by $17 \%$ and $20 \%$, respectively, during the first year post-OHT. Like the patients in our study, their patients were immunosuppressed with a CyA-based regimen. In contrast, Chin et al. (11) found LDL elevation to be rare after OHT with the mean LDL levels the same as average values for healthy historical controls. This difference may have been because of the differentially small number of patients and lipid levels included in their study compared with ours.

In the present study, the pre-OHT total cholesterol and LDL levels were lower than average values, and, although the data was unavailable for review, we suspect this was because of the severity of the pre-OHT illnesses. Post-OHT total cholesterol and LDL levels were significantly above average values for the entire follow-up period in all age groups, except for LDL levels in group 2. This may have been because of significant variation within the levels of that group. To our knowledge, this report is the first to have examined many post-OHT 
lipoprotein profiles for each patient, numbering nearly 3000 data points, and to have compared age-group specific profiles over an average follow-up period spanning $>5 \mathrm{yr}$. Previous studies have not reported the effect of age on lipid profiles. Our study showed that post-OHT hyperlipidemia occurs independent of age. The mixed model analysis revealed that, while each age group had statistically different total cholesterol curves over time, at any given post-OHT time point, each age group, even those $\leq 4 \mathrm{yr}$ of age, had absolute levels significantly above the NCEP means.

In addition to investigating the effect of age on hyperlipidemia, we assessed the various iatrogenic factors associated with hyperlipidemia in these patients. In a study examining immunosuppressive effects, Becker et al. (1) found prednisone and CyA exposure to be associated with elevated total cholesterol and LDL levels in adult heart transplant recipients. Data from our study corroborated these findings, showing that both CyA level and prednisone dose were positively associated with total cholesterol and LDL levels. Other studies in adults also confirm that prednisone and CyA are associated with hyperlipidemia and that these immunosuppressive agents likely either increase the production or decrease catabolism of lipoproteins (2-5). OHT patients may benefit from steroid-free immunosuppressive regimens and/or use of tacrolimus-based immunosuppression, which is associated with less hyperlipidemia compared with CyA $(3,14,15)$.

In contrast, our study found no association between AZA or MMF and hyperlipidemia. Although this is the first time this association has been studied in children, Akhlaghi et al. (5) found no association of AZA use with lipid levels in adult heart transplant patients.

Furthermore, the present study revealed postOHT HDL levels to be similar to normal values. In contrast, Chin et al. (11) found that post-OHT HDL levels were abnormally low. They evaluated 28 patients with 71 lipid determinations and found the HDL to be $43.2 \pm 14.7 \mathrm{mg} / \mathrm{dL}$ with the median rank well below the 25 th percentile. Again, this may have been because of the small sample size in their study. In agreement with our findings, however, these investigators also showed that pre- and post-OHT triglyceride levels were higher than normal values. This is a potential risk factor for $\mathrm{CAV}$, as demonstrated by Valantine (16), who found a trend toward higher triglyceride levels in patients with coronary artery intimal thickening. In her study, results of 375 simultaneous intravascular ultrasound examinations and lipid measurements in
264 OHT recipients were analyzed, and triglyceride measurements at 1- and 2-yr post-OHT showed a trend toward correlation with maximum intimal thickness.

As has been shown in multiple studies of adults and children, we corroborated that statins can be used effectively in older children to reduce cholesterol and LDL levels. Total cholesterol was reduced by $16 \%$ and LDL by $24 \%$ after the introduction of a statin. This is similar to a $20 \%$ decline in cholesterol and a $26 \%$ decline in LDL found by Chin et al. (17) in pediatric OHT patients. It was not the purpose of this study to fully evaluate the effects of statins; therefore, efficacy and safety profiles across age groups were not investigated. In addition, because of the small sample size, we were unable to investigate efficacy differences between statins.

\section{Potential clinical implications}

The present study confirms that children of all ages, even those $<4$ yr of age, who are post-OHT, particularly those on CyA-based immunosuppression, should be monitored for hyperlipidemia. Treatment of hyperlipidemia with a statin should be considered, as this may not only control the lipid derangements but also, based on the findings of other cited studies, may decrease the progression of associated CAV. In addition to lipid lowering effects, statins have multiple antioxidant, anti-inflammatory, and immunomodulatory effects, which may enhance vascular endothelial function, improve vascular health, and slow the progression of CAV (18-20). Statin safety, however, has not been established in children $<8-10 \mathrm{yr}$ of age. The safety of atorvastatin, lovastatin, and simvastatin has been established for children $\geq 10 \mathrm{yr}$ of age with familial hypercholesterolemia (21-23), and pravastatin is safe for these children $\geq 8 \mathrm{yr}$ of age (24). While one of our younger patients with elevated total cholesterol received a statin, our center does not routinely place children $<10 \mathrm{yr}$ of age on statins.

As safety data is lacking, it is not known whether the risk:benefit ratio would favor the use of statins in all pediatric OHT age groups (i.e. those $\leq 8-10 \mathrm{yr}$ of age) for the treatment of hypercholesterolemia. Furthermore, safety has not been established for use of statins in pediatric patients with normal or only slightly elevated total cholesterol and LDL levels. This is becoming a more widely discussed issue among pediatric transplant physicians, as our adult colleagues now routinely prescribe statins, regardless of lipid levels, for their 'coronary protective effects.' In pediatric patients, particularly those who are 
prepubertal, a significant amount of cholesterol is needed for brain maturation and differentiation, and depletion of cholesterol in growing tissue leads to aberrant development (25). Therefore, in contrast to the new adult practice, caution must be exercised before statin use is recommended for all pediatric patients, as 'subtherapeutic' lipid levels within the more vulnerable age groups could adversely impact neuro-somatic development.

\section{Limitations}

Although this study included a large number of patients with many post-OHT lipid levels, it was limited by the relatively small number of patients within each age group. Despite this, age was not found to be associated with lipid levels in further analyses, which examined the entire study population as one group. Furthermore, secondary to a lack of adequate therapies for CAV and to a potentially unfavorable risk:benefit ratio, coronary angiography was not routinely performed during the study period. The association of hyperlipidemia with CAV, therefore, could not be assessed. In addition, as it was not the purpose of this study to fully evaluate the effects of statins, efficacy and safety profiles across age groups were not investigated.

\section{Conclusion}

In this study, we report the results of a systematic analysis evaluating the effects of age on hyperlipidemia in pediatric post-OHT patients. We also investigated the various factors contributing to hyperlipidemia in these patients and assessed its reversibility with statin use. Our results suggest that pediatric OHT patients in all age groups, even those $<4 \mathrm{yr}$ of age, develop hyperlipidemia and that CyA and prednisone are positively correlated with increased total cholesterol and LDL levels. Coupled with their antioxidant, anti-inflammatory, and immunomodulatory effects, statins may be beneficial to hyperlipidemic OHT patients of all ages, once more safety data is available for children $<10 \mathrm{yr}$ of age. In contrast to adult standard practice, these agents cannot be recommended in children with normal total cholesterol and LDL levels, until additional studies demonstrate that they do not adversely impact neuro-somatic growth.

\section{References}

1. Becker DM, Chamberlain B, Swank R, et al. Relationship between corticosteroid exposure and plasma lipid levels in heart transplant recipients. Am J Med 1988: 85: 632-638.
2. Ballantyne CM, Podet EJ, Patsch WP, et al. Effects of cyclosporin therapy on plasma lipoprotein levels. JAMA 1989: 262: 53-56.

3. BaAn CC, Van Riemsdijk-Van Overbeeke IC, Balk AHMM, et al. Conversion from cyclosporin A to tacrolimus is safe and decreases blood pressure, cholesterol levels and TGF-B1 type I receptor expression. Clin Transplant 2001: 15: 276-283.

4. Ballantyne CM, Masri BE, Morrisett JD, Torre-Amione G. Pathophysiology and treatment of lipid perturbation after cardiac transplantation. Curr Opin Cardiol 1997: 12: 153160 .

5. Akhlaghi F, Jackson CH, Parameshwar J, Sharples LD, TRULL AK. Risk factors for the development and progression of dyslipidemia after heart transplantation. Transplantation 2002: 73: 1258-1264.

6. Alonso DR, Starek PK, Minick CR. Studies on the pathogenesis of atheroarteriosclerosis induced in rabbit cardiac allografts by the synergy of graft rejection and hypercholesterolemia. Am J Pathol 1977: 87: 415-435.

7. Kapadia SR, NisSEn SE, Ziada KM, et al. Impact of lipid abnormalities in development and progression of transplant coronary disease: A serial intravascular ultrasound study. J Am Coll Cardiol 2001: 38: 206-213.

8. Behrendt D, Ganz P, Fang JC. Cardiac allograft vasculopathy. Curr Opin Cardiol 2000: 15: 422-429.

9. Boucek MM, Edwards LB, Keck BM, et al. The registry of the International Society for Heart and Lung Transplantation: Fifth official pediatric report-2001 to 2002. J Heart Lung Transplant 2002: 21: 827-840.

10. Seipelt IM, Crawford SE, Rodgers S, et al. Hypercholesterolemia is common after pediatric heart transplantation: Initial experience with pravastatin. J Heart Lung Transplant 2004: 23: 317-322.

11. Chin C, Rosenthal D, Bernstein D. Lipoprotein abnormalities are highly prevalent in pediatric heart transplant recipients. Pediatr Transplant 2000: 4: 193-199.

12. Difilippo S, Sassolas A, Sassolas F, Semiond B, Bozio A. Changes in serum cholesterol, lipoproteins and triglycerides after cardiac transplantation in children. Arch Mal Coeur Vaiss 2001: 94: 464-469.

13. National Center for Health Statistics. 2000 CDC Growth charts: United States. Available from: URL: http:// www.cdc.gov/growthcharts.

14. Expert Panel on Blood Cholesterol Levels in Children and Adolescents. National cholesterol education program: Report of the expert panel on blood cholesterol levels in children and adolescents. Pediatrics 1992: S89: 525-584.

15. Law YM, Yim R, Agatisa PK, et al. Lipid profiles in pediatric thoracic recipients are determined by the immunosuppressive regimens [abstract]. J Heart Lung Transplant 2002: 21: 172 .

16. VAlantine HA. Role of lipids in allograft vascular disease: A multicenter study of intimal thickening detected by intravascular ultrasound. J Heart Lung Transplant 1995: 14: S234-S237.

17. Chin C, Gamberg P, Miller J, Luikart H, Bernstein D. Efficacy and safety of atorvastatin after pediatric heart transplantation. J Heart Lung Transplant 2002: 21: 12131217.

18. Weis M. Cardiac allograft vasculopathy: Prevention and treatment options. Transplant Proc 2002: 34: 1847-1849.

19. Fenster BE, Tsao PS, Rockson SG. Endothelial dysfunction: Clinical strategies for treating oxidant stress. Am Heart J 2003: 146: $218-226$.

20. Jarvisalo MJ, ToikKa JO, Vasankari T, et al. HMG CoA reductase inhibitors are related to improved systemic 


\section{Armstrong et al.}

endothelial function in coronary artery disease. Atherosclerosis 1999: 147: 237-242.

21. Mccrindle BW, Ose L, Marais AD. Efficacy and safety of atorvastatin in children and adolescents with familial hypercholesterolemia or severe hyperlipidemia: A multicenter, randomized, placebo-controlled trial. J Pediatr 2003: 142: 74 80.

22. Stein EA, Illingworth DR, Kwiterovich PO, et al. Efficacy and safety of lovastatin in adolescent males with heterozygous familial hypercholesterolemia: A randomized controlled trial. JAMA 1999: 281: 137-144.
23. Dejongh S, Ose L, Szamosi T, et al. Efficacy and safety of statin therapy in children with familial hypercholesterolemia: A randomized, double-blind, placebo-controlled trial with simvastatin. Circulation 2002: 106: 2231-2237.

24. Mccrindle BW, Helden E, Cullen-Dean G, Conner WT. A randomized crossover trial of combination pharmacologic therapy in children with familial hyperlipidemia. Pediatr Res 2002: 51: 715-721.

25. Hanaka S, Abe T, Itakura H, Matsumoto A. Gene expression related to cholesterol metabolism in mouse brain during development. Brain Dev 2000: 22: 321-326. 